Original Article

\title{
COMPOSITION OF PURIFIED ANTHOCYANIN ISOLATED FROM TEAK AND IT'S IN VITRO ANTIOXIDANT ACTIVITY
}

\author{
GREESHMA MURUKAN, MURUGAN K.* \\ Plant Biochemistry and Molecular Biology Laboratory, Department of Botany, University College, Trivandrum, 695034, Kerala, India \\ Email: harimurukan@gmail.com
}

Received: 29 Apr 2017 Revised and Accepted: 22 Jul 2017

\section{ABSTRACT}

Objective: The present study evaluates purification, characterization of anthocyanin from in vitro culture of teak and its antioxidant potential.

Methods: Anthocyanin was extracted from in vitro culture, purified by using amber lite XAD column and fractionated by Liquid chromatography mass spectrometry (LC-MS/MS). Various antioxidant assays were carried such as 2,2-diphenyl-1-picryl-hydrazyl-hydrate (DPPH), 2,2'-azino-bis-3ethyl-benzothiazoline-6-sulphonic acid (ABTS), Oxygen radical absorbance capacity (ORAC), Nitric oxide (NO) and Hydrogen peroxide ( $\mathrm{H}_{2} \mathrm{O}_{2}$ ).

Results: Liquid chromatography mass spectrometry (LC-MS/MS) revealed the major fraction as cyanidin 3-(2-xylosyl-rutinoside) with unknown peaks. The amount of anthocyanin was $15.23 \mathrm{mg} / \mathrm{g}$ monomeric anthocyanin. Further, the potential antioxidant capacity of the teak anthocyanin was comparable to common vegetables and fruits. Similarly, high correlations of anthocyanin with antioxidant activity, such as oxygen radical absorbance capacity (ORAC), 2,2'-azino-bis-3-ethyl-benzothiazoline-6-sulphonic acid (ABTS), and 2,2-diphenyl-1-picryl-hydrazyl-hydrate (DPPH) (r $=0.95,0.93$, and 0.80 ) were found.

Conclusion: The high anthocyanins content and potential antioxidant activity suggests that teak anthocyanin may be applied in the food industry as a good source of natural pigments.

Keywords: Teak, Anthocyanin, Antioxidant, In vitro culture, Ethnic knowledge

(C) 2017 The Authors. Published by Innovare Academic Sciences Pvt Ltd. This is an open access article under the CC BY license (http://creativecommons.org/licenses/by/4.0/] DOI: http://dx.doi.org/10.22159/ijpps.2017v9i9.19517

\section{INTRODUCTION}

Anthocyanins are flavonoid class of phytochemicals, a group predominant in vegetables, flowers, fruits, and seeds. The flavonoids, the unique group of phenolics in foods, comprise 4000 types of $\mathrm{C}_{15}$ aromatic plant compounds with multiple substitution patterns. The common examples are cyanidin, pelargonidin, petunidin, quercetin, kaempferol, (luteolin, apigenin, myricetin, naringin, hesperetin, naringenin, catechin, epicatechin, gallocatechin and derived molecules such as genistein and daidzein. Daily intake is approximately from 0.5 to $1 \mathrm{~g}$, but variability was accounted in consuming flavonoid products [1].

Colorful anthocyanins are bioflavonoid phytochemicals. The freeradical scavenging and antioxidant capacities of anthocyanin pigments are the most highly utilized potentialities in human therapeutic targets, but, research outputs suggest that other mechanisms of reactions were also responsible for the noticed health benefits [2]. Anthocyanin also provides protection of deoxy ribonucleic acid (DNA) cleavage, estrogenic activity, enzyme inhibition, boosting immunity, anti-inflammatory activity, lipid peroxidation, decreasing capillary permeability and fragility, and membrane strengthening $[3,4]$. The position, number, and types of substitutions of the individual anthocyanin molecule was related with its bioactive properties [5] and also the structure/function relationships influence the intracellular localization of these pigments.

Induction of phytochemicals via in vitro cultures may be of demand for obtaining molecules that are not easy to synthesis or isolate from in vivo sources. Anthocyanin is of importance to the pharmaceutical industry, complemented by documented research papers that have been proven their in vitro production [1]. The role of media, physical conditions, precursors, growth regulators, and elicitors and stressors on the production of these compounds were proved.

Anthocyanin pigments as therapeutically important and have been an accepted dogma in folk lore medicine around the world. For instance, Hibiscus anthocyanins have been used in remedies for liver dysfunction and hypertension; and bilberry anthocyanins used for vision disorders, microbial infections, diarrhea, and diverse other health disorders. In many cases, the mechanism of these molecules in human health is not properly elucidated. In fact, certain cases suggest that anthocyanin activity is potentiated only as crude mixtures [6-8].

Tectona grandis L. the teak belongs to Lamiaceae, a large deciduous tree with light brown bark, leaves simple, with minute glandular dots, flowers are with a pleasant smell. The plant is most widely cultivated for valued hardwood and is native to India, Myanmar and South-East Asian countries and dominants the tropical plantation forestry. The plant is therapeutically significant to cure several disorders according to Indian herbal system of medicines like treatment of urinary discharge, bronchitis, cold and headache, in scabies, used as a laxative and sedative, as diuretic, anti-diabetic, analgesic and anti-inflammatory $[9,10]$ The reported phytochemicals were Juglone, (antimicrobial), betulin aldehyde (anti-tumor activity), lapachol [11]. In this juncture present study aims in isolation of anthocyanin from in vitro culture, its purification, fractionation and analysis of AOX potentials.

\section{MATERIALS AND METHODS}

\section{Plant material}

The healthy fresh leaves and nodes of Tectona grandis were collected from wild teak plantations of Nilambur hills, Kerala, which is a place lying between $11^{\circ} 16^{\prime} \mathrm{N}$ and $76^{\circ} 13^{\prime} \mathrm{E}$.

Chemicals

Amberlite XAD-7, 2,2-diphenyl-1-picryl-hydrazyl-hydrate free radical assay (DPPH), 2,2'-azino-bis-3-ethyl-benzothiazoline-6sulphonic acid assay (ABTS) 2,4-dichlorophenoxy acetic acid (2,4-D), naphthalene acetic acid (NAA), Kinetin and 6-benzyl-aminopurine (BAP) were obtained from Sigma-Aldrich, Banglore, India. Butylated hydroxytoluene (BHT) and Murashige and Skoog (MS) media were 
procured from Himedia, Mumbai, India. All other reagents and solvents are of analytical grade.

\section{Callus induction}

For the initial establishment of callus culture nodes and leaves were used as the source of explants. The explants were surface sterilized using mercuric chloride for $3 \mathrm{~min}$ and washed thoroughly ion distilled water and were used for callus induction. The explants were then placed on the MS media supplemented with various concentrations and combinations of 2,4-dichlorophenoxy acetic acid (2,4-D), naphthalene acetic acid (NAA), Kinetin and 6-benzylaminopurine (BAP) alone or in combinations for callus induction. The explants were cultured in test tubes and maintained in the culture room at of $22 \pm 4{ }^{\circ} \mathrm{C}$ and at a $16 \mathrm{~h}$ photoperiod. Each test tube contained single explant.

\section{Subculturing}

Observations were made till one month of inoculation. After successful callus initiation 5-mm 3 calli was taken from one-monthold callus and was placed on $20 \mathrm{ml}$ Murashige and Skoog media (MS media) with the same combination of phytohormones. For each media, there were five replicates. Observations were recorded every alternate day.

\section{Anthocyanin induction}

The different hormones play an important role in anthocyanin production. In this study different hormonal combinations were used for triggering anthocyanin production.

\section{Determination of anthocyanin content in fresh callus}

Fresh calli $(0.5 \mathrm{~g})$ was weighed in $15 \mathrm{ml}$ plastic centrifuge tube and broken to small pieces using forceps. Five millilitres of methanol containing $1 \%$ concentrated hydrochloric acid $(\mathrm{HCl})$ at $4{ }^{\circ} \mathrm{C}$ was added to the sample. The tubes were vortexed and the samples were centrifuged at $15000 \mathrm{~g}$ for $20 \mathrm{~min}$ at $4{ }^{\circ} \mathrm{C}$. Absorbance of the clear supernatant was measured at $528 \mathrm{~nm}$. Anthocyanin content was calculated according to the method described by Mori et al., [12]. Total anthocyanin yield was expressed as $\left(\mu \mathrm{g} \mathrm{g}^{-1}\right)$ fresh weight of callus.

\section{Extraction and purification of anthocyanin}

Anthocyanins were extracted with methanol containing 0.5\% hydrochloric acid ( $\mathrm{HCl})(\mathrm{v} / \mathrm{v})$. Teak leaves were also pre-soaked in water containing $0.5 \%$ hydrochloric acid $(\mathrm{HCl})$. In this case, this was done to improve the extraction yield of anthocyanin because direct methanolic extractions provide poor yield. The extraction was performed in the refrigerator at low temperatures $\left(5^{\circ} \mathrm{C}\right)$ to avoid hydrolysis of potential acyl groups in the anthocyanin structure and its degradation. After extraction, the extract was filtered, and the methanol was removed by evaporation under reduced pressure at relatively low temperatures $\left(<30^{\circ} \mathrm{C}\right)$.

\section{Liquid-liquid partition}

The combined aqueous concentrates after evaporation were purified by partition against ethyl acetate to remove chlorophylls, stilbenoids, less polar flavonoids and other non polar compounds from the mixture.

\section{Amberlite XAD-7 (adsorption chromatography)}

The aqueous extracts obtained after the liquid-liquid partition step will also contain other water soluble compounds including anthocyanins, like free sugars and aliphatic acids. These nonaromatic compounds were removed with the use of Amberlite XAD7 column chromatography.

Amberlite XAD-7 adsorbs the aromatic compounds including anthocyanins and other flavonoids in aqueous solutions, whereas free sugars and other polar non-aromatic compounds were removed by washing with distilled water until the eluted water has a neutral $\mathrm{pH}$. Then the adsorbed anthocyanins and other flavonoids were eluted using methanol containing $0.5 \%$ hydrochloric acid $(\mathrm{HCl})$ (v/v) as mobile phase [13].
Liquid chromatography-mass spectrometry (LC-MS/MS)
analysis

Subsequently, the column eluted fraction with highest anthocyanin content was used for the Liquid chromatography-mass spectrometry (LC-MS/MS) analysis. The experiment was performed on a Thermo Scientific Dionex UltiMate® 3000 RSLC system with chromategraphic separation achieved on a Thermo Scientific Acclaim ${ }^{\circledR}$ RSLC 120 C18 reversed-phase column $(2.1 \times 100 \mathrm{~mm}, 2.2 \mu \mathrm{m})$ operated at $40{ }^{\circ} \mathrm{C}$ with gradient elution at $0.5 \mathrm{ml} / \mathrm{min}$. The mobile phase consisted of three components: A) acetonitrile, B) deionized (DI) water, and C) $20 \%$ formic acid. Mobile phase C was held constant at $10 \%$ to provide $2 \%$ total formic acid in the mobile phase throughout the run. Mobile phase A was ramped from $0 \%$ to $8 \%$ from 11 to 42 min, then held for 13 min before returning to the initial composition from 55 to $60 \mathrm{~min}$. Electrospray ionization (ESI) was used as the interface and was operated in positively selected ion monitoring (SIM) mode. The probe temperature was set at $500{ }^{\circ} \mathrm{C}$ and needle voltage was set at $2000 \mathrm{~V}$. The cone voltage was set at $50 \mathrm{~V}$ for all SIM scans with a span of $0.3 \mathrm{amu}$ for each SIM

\section{Antioxidant assays (AOX)}

2,2-diphenyl-1-picryl-hydrazyl-hydrate free radical assay (DPPH)

The free radical scavenging activity was followed by the 2,2diphenyl-1-picryl-hydrazyl-hydrate (DPPH) method described by Blois [14] and the absorbance was measured at $517 \mathrm{~nm}$. The lower absorbance of the reaction mixture indicates higher free radical scavenging activity. Butylated hydroxyl toluene (BHT) was used as a standard.

\section{2,2'-azino-bis-3-ethylbenzothiazoline-6-sulphonic acid assay (ABTS)}

The 2,2'-azino-bis-3-ethylbenzothiazoline-6-sulphonic acid (ABTS) assay was performed by the method proposed by Herraiz and Galisteo [15] and is based on the oxidation of the ABTS by potassium persulfate to form a radical cation 2,2'-azino-bis-3ethylbenzothiazoline-6-sulphonic acid $\left(\mathrm{ABTS}^{+}\right)$. The absorbance was taken at $734 \mathrm{~nm}$ and the activity was expressed as percentage inhibition of 2,2'-azino-bis-3-ethylbenzothiazoline-6-sulphonic acid (ABTS) radicals.

\section{Hydrogen peroxide radical scavenging activity}

The ability of the anthocyanin to scavenge hydrogen peroxide was determined according to the method of Ruch et al., [16]. Absorbance of hydrogen peroxide at $230 \mathrm{~nm}$ was determined for a period of 10 min against a blank solution containing the phosphate buffer without hydrogen peroxide.

\section{Ferric reducing/antioxidant power (FRAP) assay}

The total antioxidant potential of the sample was determined using the ferric reducing ability of plasma by ferric reducing/antioxidant power (FRAP) assay proposed by Benzie and Strain [17]. The antioxidant capacity was expressed in ferric reducing/antioxidant power (FRAP) unit, in mmol mmol $\mathrm{Fe}_{2}{ }^{+}$. G-1calculated by linear regression curve of iron sulphate standard.

\section{Oxygen radical absorbance capacity (ORAC) assay}

Both hydrophilic and lipophilic oxygen radical absorbance capacity (ORAC) assays were carried out using Cary Eclipse fluorescence spectrophotometer following the method described by Prior et al., [18].

\section{Nitric oxide (NO) radical scavenging power}

Nitric oxide (NO) radical scavenging assay was performed as described by Jakobek et al., [19]. The absorbance was recorded at $546 \mathrm{~nm}$. Nitric oxide (NO) radical scavenging activity was calculated using a formula similar to that used for 2,2-diphenyl-1-picrylhydrazyl-hydrate (DPPH) radical scavenging assay.

\section{Statistical analysis}

All data were reported as mean \pm standard deviation of 12 replicates. 
The data were analyzed using one-way variance analysis (One Way ANOVA). All statistical analysis was performed using the SPSS 10.0 software package.

\section{RESULTS AND DISCUSSION}

The phytochemicals found in plants have different potentialities as antioxidants. Generally, antioxidant activity of the extract and the yield depends on the selected solvent. In this study, anthocyanin was isolated from in vitro culture, purified and fractionated for evaluating antioxidant potential using various assays.

\section{In vitro culture}

Sterilization with ethanol followed by $0.1 \%$ mercuric chloride $\left(\mathrm{HgCl}_{2}\right)$ solution for $5 \mathrm{~min}$ and further treatment with $3 \%$ sodium hypochlorite solution +2 drops of Tween $20+0.05 \%$ fungicide for 20 min yielded $95 \%$ contamination free cultures. While comparing with the sterilization protocol proposed by Ramesh et al., [20] this procedure was simple i.e., it involves treatment of the shoot explants with 1\% Bavastin, $0.1 \%$ Streptomycin, 70\% ethanol, $0.05 \%$ mercuric chloride, $5 \%$ sodium hypochlorite+Tween-80 and finally rinsed in sterile distilled water. Irrespective of the hormones used optimal callus induction was noticed with leaf when compared to nodal explants. This may be due to the fact that leaves are more immature and therefore highly meristematic.

In the present study, MS medium supplemented with 6-benzylaminopurine (BAP) (1 mg/l)+naphthalene acetic acid (NAA) (0.2 $\mathrm{mg} / \mathrm{l}$ ) yielded higher biomass of callus from the leaf explants followed by MS medium with $2 \mathrm{mg} / \mathrm{l}$ 2,4-dichlorophenoxy acetic acid (2,4-D)+0.5 mg/l kinetin. After $21^{\text {st }}$ day of inoculation on the culture media, significant callus induction was noticed with 6benzylaminopurine (BAP) (1 mg/l)+ naphthalene acetic acid (NAA) $(0.2 \mathrm{mg} / \mathrm{l})$ and dichlorophenoxy acetic acid $(2,4-\mathrm{D})(2 \mathrm{mg} / \mathrm{l})+$ kinetin $(0.5 \mathrm{mg} / \mathrm{l})$ for leaf and nodal explants $92.5 \%$ and $80 \%$ respectively. Fully grown callus could be maintained in both induction and basal Murashige and Skoog (MS) medium for longer periods in terms of healthy greenish and friable callus for easy multiplication.

Table 1: Hormonal combinations and percentage of callus induction in T. grandis

\begin{tabular}{|c|c|c|c|}
\hline Leaf & Concentration (mg/l) & Callus induction (\%) & Callus growth grade \\
\hline \multicolumn{4}{|c|}{ Hormonal combinations } \\
\hline MS medium & 0 & 1.8 & - \\
\hline $\mathrm{MS}+2,4-\mathrm{D}$ & 0.5 & 4 & + \\
\hline $\mathrm{MS}+2,4-\mathrm{D}$ & 1 & 13 & + \\
\hline $\mathrm{MS}+2,4-\mathrm{D}$ & 2 & 43.3 & + \\
\hline $\mathrm{MS}+2,4-\mathrm{D}$ & 3 & 25 & + \\
\hline $\mathrm{MS}+2,4-\mathrm{D}$ & 4 & 29 & + \\
\hline$M S+2,4-D$ & 5 & 31 & + \\
\hline $\mathrm{BAP}+\mathrm{NAA}$ & $0.5+0.2$ & 57 & ++ \\
\hline $\mathrm{BAP}+\mathrm{NAA}$ & $1+0.2$ & 92.5 & ++++ \\
\hline $\mathrm{BAP}+\mathrm{NAA}$ & $0.5+1$ & 50 & ++ \\
\hline $\mathrm{BAP}+\mathrm{NAA}$ & $0.5+2$ & 60 & +++ \\
\hline 2,4-D+KIN & $2+0.5$ & 73 & ++++ \\
\hline 2,4-D+KIN & $1+1$ & 60 & +++ \\
\hline 2,4-D+KIN & $1+2$ & 52 & ++ \\
\hline 2,4-D+KIN & $2+1$ & 48 & + \\
\hline 2,4-D+KIN & $3+1$ & 41 & + \\
\hline 2,4-D+KIN & $2+2$ & 5 & - \\
\hline 2,4-D+KIN & $2+3$ & 32 & + \\
\hline 2,4-D+KIN & $3+4$ & 29 & + \\
\hline 2,4-D+KIN & $4+5$ & 18 & + \\
\hline 2,4-D+KIN & $5+6$ & 13.2 & + \\
\hline $\mathrm{MS}+\mathrm{CW}(\mathrm{ml} / \mathrm{l})$ & 5 & 23 & + \\
\hline $\mathrm{MS}+\mathrm{CW}(\mathrm{ml} / \mathrm{l})$ & 10 & 25 & + \\
\hline $\mathrm{MS}+\mathrm{CW}(\mathrm{ml} / \mathrm{l})$ & 15 & 28 & + \\
\hline $\mathrm{MS}+\mathrm{CW}(\mathrm{ml} / \mathrm{l})$ & 20 & 30 & + \\
\hline
\end{tabular}

All the values are mean $(12$ replicates) \pm SD. $\mathrm{P}<0.05$ (significance at $5 \%$ level)

Table 2: Nodal culturing in MS media supplemented with different combinations of BAP and NAA in T. grandis for callus initiation

\begin{tabular}{lll}
\hline Nodal & Concentration (mg/l) & \\
\hline Hormonal combinations & & Callus (\%) \\
MS medium & 0 & 0 \\
BAP+NAA & $0+0$ & 0 \\
BAP+NAA & $0.5+0$ & 9.5 \\
BAP+NAA & $0.5+0.2$ & 22.7 \\
BAP+NAA & $1+0.2$ & 32 \\
BAP+NAA & $1.5+0.2$ & 36 \\
BAP+NAA & $2+0.2$ & 44 \\
BAP+NAA & $2.5+0.2$ & 40 \\
BAP+NAA & $0.5+0.5$ & 50 \\
BAP+NAA & $1+0.5$ & 64 \\
BAP+NAA & $1.5+0.5$ & 74 \\
BAP+NAA & $2+0.5$ & 80 \\
BAP+NAA & $2.5+0.5$ & 40 \\
\hline
\end{tabular}

All the values are mean (12 replicates) \pm SD. $\mathrm{P}<0.05$ (significance at $5 \%$ level) 
Narasimhan et al. [21] attempted in vitro culture of teak, jack, mulberry in Murashige and Skoog (MS) medium containing glycine and gibberellic acid. Similarly, Omar and Novak, Rao and Vaidyanath, and Litz et al. [22-24] were successfully established calli in date palm, sesamum and gymnosperm species with the combinations of dichlorophenoxy acetic acid (2,4-D) and Kinetin. The present study also reports callus initiation and multiplication with leaf and nodal teak explants with 6-benzylaminopurine (BAP)+naphthalene acetic acid (NAA) and dichlorophenoxy acetic acid (2,4-D)+kinetin in MS media. Similarly, enhanced rate of callusing in Aquilaria malaccensis has been reported by Saikia et al. [25] using dichlorophenoxy acetic acid (2,4-D) and kinetin combinations.

As the second phase, sub culturing of calli was attempted with dichlorophenoxy acetic acid (2, 4-D), kinetin (KIN), 6benzylaminopurine (BAP), naphthalene acetic acid (NAA), coconut water either singly or in combinations. Interestingly, dichloro- phenoxy acetic acid (2,4-D)+kinetin (KIN) combination did not enhance callus growth but, irrespective of explants, the combination began to alter the colour from $30^{\text {th }}$ day of inoculation from brownish to pink pigmentation. The results suggest that dichlorophenoxy acetic acid (2,4-D) and kinetin (KIN) probably induce anthocyanin biosynthetic pathway. It is worth to note that the medium containing $1.0 \mathrm{mg} / \mathrm{l}$ with dichlorophenoxy acetic acid (2, 4-D) and $2.0 \mathrm{mg} / \mathrm{l}$ kinetin (KIN) yield callus with remarkable anthocyanin contents from leaf explants.

Interestingly, leaf explants yielded 0.06 to $15.23 \mathrm{mg} / \mathrm{g}$ anthocyanin levels. The results tempt to state that 6-benzylaminopurine (BAP)+ naphthalene acetic acid (NAA) produced optimal callus growth whereas with dichlorophenoxy acetic acid (2,4-D)+kinetin (KIN) yielded remarkable anthocyanin content. It is interesting to state that there is an inverse correlation between callus growth and anthocyanin accumulation.

Table 3: Sub-culturing of calli in MS media supplemented with different hormonal combinations and respective anthocyanin content in T. grandis

\begin{tabular}{|c|c|c|}
\hline Leaf & Concentration (mg/l) & Anthocyanin content (mg/g callus) \\
\hline \multicolumn{3}{|c|}{ Hormonal combinations } \\
\hline MS medium & 0 & 0 \\
\hline $\mathrm{MS}+2,4-\mathrm{D}$ & 0.5 & 0.06 \\
\hline$M S+2,4-D$ & 1 & 0.09 \\
\hline$M S+2,4-D$ & 2 & 0.12 \\
\hline $\mathrm{MS}+2,4-\mathrm{D}$ & 3 & 0.19 \\
\hline $\mathrm{MS}+2,4-\mathrm{D}$ & 4 & 0.23 \\
\hline $\mathrm{MS}+2,4-\mathrm{D}$ & 5 & 0.24 \\
\hline $\mathrm{BAP}+\mathrm{NAA}$ & $0.5+0.2$ & 0.27 \\
\hline $\mathrm{BAP}+\mathrm{NAA}$ & $1+0.2$ & 6.84 \\
\hline $\mathrm{BAP}+\mathrm{NAA}$ & $0.5+1$ & 3.3 \\
\hline $\mathrm{BAP}+\mathrm{NAA}$ & $0.5+2$ & 4.2 \\
\hline 2,4-D+KIN & $1+1$ & 8.92 \\
\hline 2,4-D+KIN & $1+2$ & 15.23 \\
\hline 2,4-D+KIN & $2+1$ & 9.8 \\
\hline 2,4-D+KIN & $3+1$ & 7.6 \\
\hline 2,4-D+KIN & $2+2$ & 4.2 \\
\hline 2,4-D+KIN & $2+3$ & 3 \\
\hline 2,4-D+KIN & $3+2$ & 2.6 \\
\hline 2,4-D+KIN & $3+4$ & 3.8 \\
\hline 2,4-D+KIN & $4+5$ & 4.9 \\
\hline 2,4-D+KIN & $5+6$ & 2.59 \\
\hline $\mathrm{MS}+\mathrm{CW}(\mathrm{ml} / \mathrm{l})$ & 5 & 0.38 \\
\hline $\mathrm{MS}+\mathrm{CW}(\mathrm{ml} / \mathrm{l})$ & 10 & 0.41 \\
\hline $\mathrm{MS}+\mathrm{CW}(\mathrm{ml} / \mathrm{l})$ & 15 & 0.42 \\
\hline $\mathrm{MS}+\mathrm{CW}(\mathrm{ml} / \mathrm{l})$ & 20 & 0.28 \\
\hline
\end{tabular}

All the values are mean (12 replicates) \pm SD. $\mathrm{P}<0.05$ (significance at $5 \%$ level)

Meyer and Van-Staden [26] induced anthocyanin from callus cultures of Oxalis linearis using the same combination. Taha et al. [27] obtained similar anthocyanin content from calli cultures of ornamental plants. Maharik et al. [28] also noticed similar feature in in vitro culture of Cratae gussinaica.

\section{Extraction and quantification of anthocyanin}

The anthocyanin from the pigmented callus were extracted and quantified which showed $15.23 \mathrm{mg} / \mathrm{g}$ monomeric anthocyanin content. From the present study, it can be confirmed that the induction of anthocyanin production from the callus can be enhanced by using the hormones dichlorophenoxy acetic acid $(2,4$ D) and kinetin (KIN)

\section{Purification and fractionation by Liquid chromatography-mass spectrometry (LC-MS/MS)}

Subsequently, the anthocyanins extracted from the pigmented callus were subjected to purification by Amberlite-XAD column. The eluted fraction with highest anthocyanin content was further subjected to LCMS/MS analysis for the identification of key components in it. The major anthocyanin eluted from teak callus at 2.5-3.9 min. Based on the comparison with literature data, the peak corresponding to $\mathrm{m} / \mathrm{z}$ at 727.5 was identified as cyanidin 3 -(2-xylosylrutinoside). The remaining peaks at $\mathrm{m} / \mathrm{z} 681.5,623.2,439.2$ depicted the fragments of the above mentioned anthocyanidin. Two unknown non comparable peaks were also obtained from the analysis.

\section{Antioxidant assays (AOX)}

2,2-diphenyl-1-picryl-hydrazyl-hydrate (DPPH) assay is one of the reliable method for analyzing the antioxidant potential of phytochemicals. It is a stable free radical that receives an electron or hydrogen, with a subsequent change from a violet to pale yellow colour in solution, and has been commonly employed to evaluate the free radical-scavenging power.

The reducing capacity of the 2,2-diphenyl-1-picryl-hydrazyl-hydrate (DPPH) radical was quantified by a decrease in OD at $517 \mathrm{~nm}$ induced by the phytochemical. Table 4 displays the 2,2-diphenyl-1picryl-hydrazyl-hydrate (DPPH) scavenging potential of the purified anthocyanin of teak. Concentration dependent antioxidant (AOX) potential was noticed with teak anthocyanin $(p \leq 0.05)$ i.e., at 5 $\mu \mathrm{g} / \mathrm{ml}$ the $\%$ of inhibition was $42.7 \pm 0.87$ whereas at $25 \mu \mathrm{g} / \mathrm{ml}$ the respective value was $96.5 \pm 0.87(\mathrm{p} \leq 0.05)$. The $\mathrm{IC}_{50}$ value of anthocyanin and that of ascorbate were 7.34 and $25 \mu \mathrm{g} / \mathrm{ml}$ respectively. 
Table 4: Percentage of DPPH radical scavenging effect of anthocyanin with various concentrations

\begin{tabular}{ll}
\hline Concentration $(\boldsymbol{\mu g} / \mathbf{m l})$ & DPPH (\%) \\
\hline 5 & $42.7 \pm 0.87$ \\
10 & $64 \pm 1.2$ \\
15 & $70 \pm 3.8$ \\
20 & $84.43 \pm 4.7$ \\
25 & $96.5 \pm 0.87$ \\
30 & $97.2 \pm 0.99$ \\
Ascorbate (25) & $50 \pm 0.54$ \\
BHT (25) & $48 \pm 0.18$ \\
\hline
\end{tabular}

All the values are mean (12 replicates) \pm SD. $\mathrm{P}<0.05$ (significance at $5 \%$ level)

Ferric reducing/antioxidant power (FRAP) assay estimate the reducing potential of an antioxidant reacting with a ferric tripyridyltriazine (Fe3+-TPTZ) complex to form a coloured ferrous tripyridyltriazine (Fe2+-TPTZ). The reducing properties associated with the presence of phytochemical exert their action by breaking the free radical chain through donating hydrogen atom. Ferric reducing/antioxidant power (FRAP) assay showed positive correlation between reducing power and anthocyanin content (table 5) i.e., the $\mathrm{IC}_{50}$ value of anthocyanin was $19.4 \mu \mathrm{g} / \mathrm{ml}$. Generally, phenolics have redox powers, therefore function as reducers, hydrogen donors, and singlet oxygen scavengers i.e., redox potential of phenolics tune the antioxidant potentials in plant extracts [29]. Adedapo et al., [30] evaluated antioxidant (AOX) potential of Bidens pilosa and Chenopodium album using acetone and methanol extract showed high ferric reducing/antioxidant power (FRAP) activity in comparison to aqueous extracts. Tawaha et al. [31] have recorded high variation in the antioxidant (AOX) potential of the aqueous and methanolic extracts of the Jordanian plant species analyzed and interpreted the results due to the difference in the solubility of phytochemicals extracted from non-polar to polar solvents.

Table 5: Percentage of ferric reducing antioxidant power of anthocyanin with various concentrations

\begin{tabular}{ll}
\hline Concentration $(\boldsymbol{\mu g} / \mathbf{m l})$ & FRAP (\%) \\
\hline 5 & $23 \pm 0.2$ \\
10 & $37 \pm 2.6$ \\
15 & $44.4 \pm 1.1$ \\
20 & $52.5 \pm 5.2$ \\
25 & $64 \pm 3.8$ \\
30 & $69.8 \pm 0.67$ \\
Ascorbate (25) & $84.7 \pm 6.9$ \\
BHT (25) & $78 \pm 0.12$ \\
\hline
\end{tabular}

All the values are mean (12 replicates) \pm SD. $\mathrm{P}<0.05$ (significance at $5 \%$ level)

2,2-diphenyl-1-picryl-hydrazyl-hydrate (DPPH) assay was stable for evaluating the free radical-scavenging power of anthocyanin. But, it depends upon many components like reaction time, the nature of the polyphenol, and the redox potential of the molecule. 2,2'-azinobis-3-ethylbenzothiazoline-6-sulphonic acid (ABTS) radicals are highly reactive radical with fast when compared to the DPPH radicals. The reaction comprise reduction of the bluish-green 2,2'azino-bis-3-ethylbenzothiazoline-6-sulphonic acid (ABTS) radical by hydrogen-donating molecule, and the scavenging of the 2,2'-azinobis-3-ethylbenzothiazoline-6-sulphonic acid (ABTS) radical is evaluated by the OD at $600 \mathrm{~nm}$.

The purified anthocyanin of teak showed the highest 2,2'-azino-bis3-ethylbenzothiazoline-6-sulphonic acid (ABTS) value with 25 $\mu \mathrm{g} / \mathrm{ml}$ anthocyanin i.e., $90.43 \pm 2.4$ (table 6) and was more or less at par with the synthetic antioxidant ascorbate $92.7 \pm 3.7(p \leq 0.05)$.

Table 6: Percentage of ABTS radical scavenging capacity of anthocyanin with various concentrations

\begin{tabular}{ll}
\hline Concentration $(\mu \mathrm{g} / \mathrm{ml})$ & ABTS (\%) \\
\hline 5 & $27.9 \pm 0.92$ \\
10 & $50 \pm 3.8$ \\
15 & $65 \pm 0.64$ \\
20 & $79 \pm 4.8$ \\
25 & $90.43 \pm 2.4$ \\
30 & $92 \pm 0.99$ \\
Ascorbate (25) & $92.7 \pm 3.7$ \\
BHT (25) & $60 \pm 0.32$ \\
\hline
\end{tabular}

All the values are mean (12 replicates) \pm SD. $\mathrm{P}<0.05$ (significance at $5 \%$ level)

Oxygen radical absorbance capacity (ORAC) assay is unique since it scavenges a biologically analogue radical source. The merit of this is that it couples the inhibition time and its degree of radical generation, as it takes the oxidation event to completion and uses the area of the curve to estimate the antioxidant power [32]. The total oxygen radical absorbance capacity (ORAC) antioxidant activity of teak anthocyanin was marginally less than synthetic antioxidant. However, the oxygen radical absorbance capacity (ORAC) value was comparable with the values of fruits and vegetables consumed around the world. Interestingly, cooked foods also have significant antioxidant activity, but with reduced antioxidant activity, which could be due to the structural loss of polyphenolics and to the formation of other related less reactive antioxidants via Maillard reaction products or pyrolysis products.

Further, antioxidant power using the 2,2'-azino-bis-3-ethylbenzothiazoline-6-sulphonic acid (ABTS) radical cation was compared to those derived from the oxygen radical absorbance capacity (ORAC) assay based on the reduction of peroxyl radical by hydrogen-donating antioxidant molecules. The value was $642 \mu \mathrm{mol} \mathrm{TE} / \mathrm{g}$ (table 7). 
Table 7: Effect of various concentrations of anthocyanin on oxygen radical scavenging activity

\begin{tabular}{ll}
\hline Concentration $(\boldsymbol{\mu g} / \mathbf{m l})$ & ORAC $(\boldsymbol{\mu m o l ~ T E} / \mathbf{g})$ \\
\hline 5 & $490 \pm 3.7$ \\
10 & $510 \pm 2.8$ \\
15 & $525 \pm 2.5$ \\
20 & $584 \pm 3.2$ \\
30 & $609 \pm 3.5$ \\
Ascorbate $(25)$ & $642 \pm 4.0$ \\
BHT $(25)$ & $742 \pm 2.8$ \\
\hline
\end{tabular}

All the values are mean (12 replicates) \pm SD. $\mathrm{P}<0.05$ (significance at $5 \%$ level)

The diverse antioxidant activities obtained from the various assays may reflect a relative difference in the ability of anthocyanin to quench and reduce 2,2'-azino-bis-3-ethylbenzothiazoline-6-sulphonic acid (ABTS) and 2,2-diphenyl-1-picryl-hydrazyl-hydrate (DPPH) radicals.

Commonly, polyphenols are highly correlated with antioxidant potential. Fruits and vegetables contain a mixture of polyphenols and therefore display more antioxidant activity. Nevertheless, in the present work, the results show that the oxygen radical absorbance capacity (ORAC), 2,2'azino-bis-3-ethylbenzothiazoline-6-sulphonic acid (ABTS) and 2,2diphenyl-1-picryl-hydrazyl-hydrate (DPPH) values were strongly correlated with the anthocyanin content $(r=0.9499,0.9251,0.8081)$.

Many reports were published regarding the phenolics and antioxidant capacities of plant extracts, fruits, and vegetables. Lipophilic and hydrophilic antioxidant (AOX) power of common foods in the USA showed a strong positive linear relationship between phenols and the antioxidant capacity of fruits and vegetables [33]. Pomegranate juice ellagitannin was compared for its antioxidant potency via 2,2diphenyl-1-picryl-hydrazyl-hydrate (DPPH), oxygen radical absorbance capacity (ORAC) and ferric reducing/antioxidant power (FRAP) assays; the order of antioxidant (AOX) activity was consistent across the different methods, except oxygen radical absorbance capacity (ORAC) method [34]. Similarly, phenolics composition of European fruits was correlated with antioxidant activity by Borges et al. [35]. Their study proved that ellagitannins, as potential antioxidants in pomegranate juice. Pillai et al. [36] quantified polyphenolic content and antioxidant $(\mathrm{AOX})$ power of potato tubers using the oxygen radical absorbance capacity (ORAC), 2,2-diphenyl-1-picryl-hydrazyl-hydrate (DPPH) assays especially with in purple-fleshed potato tubers and compared to other vegetables.

\section{Hydrogen peroxide $\left(\mathrm{H}_{2} \mathrm{O}_{2}\right)$ scavenging activity}

Purified teak anthocyanin showed significant scavenging activity of hydrogen peroxide $\left(\mathrm{H}_{2} \mathrm{O}_{2}\right)$ in a dose dependent manner $\left(\mathrm{r}^{2}=0.990\right)$, with an $\mathrm{IC}_{50}$ value of $23.53 \mu \mathrm{g} / \mathrm{ml}$, whereas the $\mathrm{IC}_{50}$ value for ascorbate was $27.8 \mu \mathrm{g} / \mathrm{ml}\left(\mathrm{r}^{2}=0.993\right)$ (table 8). Hydrogen peroxide $\left(\mathrm{H}_{2} \mathrm{O}_{2}\right)$ is a weak oxidising agent and can directly inactivate enzymes by the oxidation of thiol groups. $\mathrm{H}_{2} \mathrm{O}_{2}$ can cross cell membranes drastically in to the cell and likely reacts with $\mathrm{Fe}^{2+}, \mathrm{Cu}^{2+}$ ions, to form hydroxyl radicals, a powerful oxidizing agent. This may leads to toxic effects. Anthocyanin acts as free radical scavenger due to their hydrogen-donating and scavenging potentiality [32].

Table 8: Effect of various concentrations of anthocyanin on hydrogen peroxide scavenging

\begin{tabular}{ll}
\hline Concentration $(\boldsymbol{\mu g} / \mathbf{m l})$ & $\mathbf{H}_{2} \mathbf{O}_{2}(\mathbf{\%})$ \\
\hline 5 & $14.8 \pm 0.38$ \\
10 & $23.7 \pm 0.52$ \\
15 & $35 \pm 0.88$ \\
20 & $42.7 \pm 0.97$ \\
25 & $54.9 \pm 2.8$ \\
30 & $60 \pm 0.77$ \\
Ascorbate (25) & $46 \pm 1.2$ \\
BHT (25) & $40 \pm 4.1$ \\
\hline
\end{tabular}

All the values are mean (12 replicates) \pm SD. $\mathrm{P}<0.05$ (significance at $5 \%$ level)

\section{Nitric oxide (NO) radical scavenging assay}

Nitric oxide (NO) radical quenching activity of purified teak anthocyanin was detected and compared with the ascorbate. The anthocyanin exhibited the maximum inhibition per cent of 267 at a concentration of $100 \mu \mathrm{g} / \mathrm{ml}$, with an $\mathrm{IC}_{50}$ value of $43.51 \mu \mathrm{g} / \mathrm{ml}$, in a concentrationdependent manner $\left(r^{2}=0.977\right)$. However, ascorbate exhibited significant inhibition per cent of 189 , with an $\mathrm{IC}_{50}$ value of $31 \mu \mathrm{g} / \mathrm{ml}(\mathrm{r} 2=0.955)$ (table 9). The scavenging potential of the anthocyanin against nitric oxide (NO) was measured by its potentiality to inhibit the formation of nitrogen dioxide $\left(\mathrm{NO}_{2}\right)$ through direct competition with oxygen and oxides of nitrogen in the reaction mixture [19]. The decrease in the amount of the nitric oxide (NO) radical was at par with ascorbate, which confirms the antioxidant potential of the anthocyanin. Nitric oxide (NO) is a potent pleiotropic mediator of physiological reactions in living organisms such as smooth muscle relaxation, neuronal signalling, inhibition of platelet aggregation and regulation of cell-mediated toxicity. Easily diffusible free radical that modulates effector molecule in various biological processes, including neuronal communication, vasodilatation and microbicidal and anticancer events [37]. Moreover, in pathologenicity, nitric oxide (NO) reacts with $\mathrm{O}_{2}$ and forms potentially cytotoxic reactive molecules, such as peroxynitrite.

Table 9: Effect of various concentrations anthocyanin on nitric oxide radical scavenging

\begin{tabular}{ll}
\hline Concentration $(\boldsymbol{\mu g} / \mathbf{m l})$ & NO (\%) \\
\hline 5 & $5.3 \pm 0.05$ \\
10 & $17.6 \pm 0.15$ \\
15 & $24.3 \pm 0.84$ \\
20 & $30.3 \pm 0.64$ \\
25 & $35 \pm 0.18$ \\
30 & $41.3 \pm 0.64$ \\
Ascorbate (25) & $45.7 \pm 0.73$ \\
BHT $(25)$ & $38.8 \pm 0.21$ \\
\hline
\end{tabular}

All the values are mean (12 replicates) \pm SD. $\mathrm{P}<0.05$ (significance at $5 \%$ level) 
Generally, antioxidants are potential in blocking the free radical chain reaction and are considered as effective. Further, phytochemicals possess aromatic or phenolic rings and capable of donating hydrogen atom to free radicals formed during oxidation and these intermediates are stable due to resonance delocalization of the extra electron within the aromatic ring and subsequent formation of stable quinones [38]. Potential phenolic antioxidants have low oxidation-reduction caliber and possess hydroxyl $(\mathrm{OH})$ groups in the ortho-position on the B phenolic ring. In addition, phenolics with more than one hydroxyl group like catechin, are reactive than those with only one. Interestingly, phenolic compounds are not prone to molecular oxygen reactions. Dietary antioxidant potentiality is largely dependent on their bioavailability, which is, in turn, influenced by digestion and complex metabolic reactions occur in the gut. Further, synergistic and antagonistic events occur between food ingredients also dominates antioxidant effectiveness [39].

Nile et al., [38] compared anthocyanin content and antioxidant capacity of grape varieties using high performance liquid chromatography (HPLC) and 2,2-diphenyl-1-picryl-hydrazylhydrate (DPPH), ferric reducing/antioxidant power (FRAP) and 2,2'azino-bis-3-ethylbenzothiazoline-6-sulphonic acid (ABTS) assays, respectively. The major anthocyanins were malvidin-3-glucoside, delphinidin-3-glucoside, petunidin-3-glucoside, cyaniding-3glucoside, and peonidin-3-glucoside with the total anthocyanin content ranging from $181.2 \mathrm{mg} / 100 \mathrm{~g}$ (Vidal Black) to $716.4 \mathrm{mg} / 100$ g FW (Catawba). Similarly there, antioxidant (AOX) potential showed variations. Jakobek et al., [19] also analyzed anthocyanin content and antioxidant activity of various red fruit juices.

Kalita and Jayanty [37] compared potato tubers with purple-and red-colored flesh with polyphenol-rich fruits, blueberries and pomegranate juice. The range of total phenolics total anthocyanins, and total flavonoids were $(4482-11189 \mu \mathrm{g} / \mathrm{g}),(1889-6289 \mu \mathrm{g} / \mathrm{g})$, and $(140-503 \mu \mathrm{g} / \mathrm{g})$, respectively. Similarly antioxidant AOX was also compared. Pasko et al., [40] analyzed total antioxidant capacity, total phenolic contents and anthocyanins contents in Amaranthus cruentus and Chenopodium quinoa seeds and sprouts and recommended as good source of antioxidants due to their high antioxidant activity. Dai et al., [41] evaluated antioxidative and chelating properties of anthocyanins in Azolla imbricata induced by cadmium. $\mathrm{EC}_{50}$ values of 2,2-diphenyl-1-picryl-hydrazyl-hydrate (DPPH) radicals scavenging, 2,2'-azino-bis-3-ethylbenzothiazoline-6sulphonic acid (ABTS) radicals scavenging, reducing power and $\beta$ carotene bleaching assay were $19.08,10.69,40.93$, and $44.19 \mu \mathrm{g} \cdot \mathrm{mL}-$ 1, respectively. Nikkhah et al., [42] measured in vitro antioxidant activity of Morus alba var. nigra by superoxide anion radical assay of the superoxide anion radicals. Antioxidant capacity increased with increase in concentration of extract. Yancheva et al., [43] confirmed that polyphenol derivatives of olive leaves with high antioxidant activity. TPC varied between $9.2 \pm 0.5$ to $16.4 \pm 0.5 \mathrm{mg} \mathrm{GAE} * \mathrm{gDW}-1$. Antioxidant capacity was determined by four methods 2,2-diphenyl1-picryl-hydrazyl-hydrate (DPPH), 2,2'-azino-bis-3-ethylbenzothiazoline-6-sulphonic acid (ABTS), ferric reducing/ antioxidant power (FRAP) and cupric reducing antioxidant capacity (CUPRAC). Figueiredo and Lima [44] evaluated antioxidant activity of anthocyanins from Sideroxylon obtusifolium fruits using 2,2diphenyl-1-picryl-hydrazyl-hydrate (DPPH) scavenging activity. Anthocyanins content were higher in the husks (236.15 mg cyanidin-3-glucoside $100 \mathrm{~g}-1 \mathrm{fw}$ ) than pulp (30.49 mg cyanidin-3glucoside $100 \mathrm{~g}-1 \mathrm{fw}$ ).

The results showed that the potential free radical scavenging increase with the increase of concentration used and the reaction time. Radovanovic et al., [45] reported 2,2-diphenyl-1-picrylhydrazyl-hydrate (DPPH) scavenging ability of tested wines and was confirmed $\left(\mathrm{r}^{2}=0.9619\right)$. The significant correlations were obtained between antiradical activity and the sum of 3-monoglucoside $\left(\mathrm{r}^{2}=\right.$ $0.95594)$, the sum of 3 -acetyl-3-glucoside $\left(r^{2}=0.9728\right)$ and the sum of p-coumaryl-3-glucoside $\left(r^{2}=0.8873\right)$ of wine samples. Thus, in wines it can be concluded that, the anthocyanin composition can be used as biochemical marker for the authenticity of red grape cultivar and their corresponding single-cultivar wine. Saha and Verma [46] proved antioxidant activity of polyphenolic extract of Terminalia chebula fruits. Ge and Ma [47] analyzed composition and antioxidant activity of anthocyanins isolated from Yunnan edible roses.

Natural antioxidants play an important role to neutralize the free radicals generated within cells [48]. In recent days, there is an emerging trend of evaluating medicinal plants for bioactive compounds as a basis for future pharmacological studies. Many studies reported that the plant derived antioxidants scavenge free radicals and modulate oxidative stress [49, 50]. Pavithra et al., [51] evaluated the in vitro antioxidant property of flavonoid rich fraction from the whole plant of Wedelia chinensis and found that it possess significant antioxidant potentiality that can protect the cells from oxidative damage. A similar study was also reported by Packialakshmi et al., [52] in Auricularia polytricha, in which the plant exhibited antioxidant activity in a dose dependent manner and it contain a significant amount of secondary metabolites such as phenol and flavonoids.

Recent research suggests that the mechanism of action of antioxidants and their role in disease onset or progression via cellular signaling processes and control of gene expression. Antioxidants and reactive oxygen species (ROS) co-exist in a finely tuned balance that ensures normal functioning of the human body. Nutrigenomics focus epigenomics on studying the heritable changes in gene expression induced by dietary antioxidants/nutrients as well as interactions between the genome and these. Role of anthocyanins as bioactive dietary compounds have in regulation of epigenetic modifications that result in significant health benefits

\section{CONCLUSION}

Anthocyanins are proven biomolecules in plants. Teak anthocyanin was isolated from standardized in vitro cultures, purified and fractionated by Liquid chromatography mass spectrometry (LCMS/MS) analysis. Subsequently, their antioxidant (AOX) potential was analyzed through 2,2-diphenyl-1-picryl-hydrazylhydrate (DPPH), ferric reducing/antioxidant power (FRAP), 2,2'azino-bis-3-ethylbenzothiazoline-6-sulphonic acid (ABTS), Hydrogen peroxide scavenging $\left(\mathrm{H}_{2} \mathrm{O}_{2}\right)$, oxygen radical absorbance capacity (ORAC) and Nitric oxide(NO) radical scavenging power. Interestingly varied potentials were noticed. $\mathrm{IC}_{50}$ values were comparable with synthetic antioxidants (AOXs) such as ascorbate and butylated hydroxyl toluene (BHT). Future studies are planned to evaluate its non-toxicity and hepatoprotective roles using rat models.

\section{ABBREVIATION}

2,4-D-2,4-dichlorophenoxy acetic acid, ABTS-2,2'-azino-bis-3ethylbenzothiazoline-6-sulphonic acid, AOX-antioxidant, BAP-6benzylaminopurine, BHT-butylated hydroxytoluene, CUPRACcupric reducing antioxidant capacity, DNA-deoxy ribonucleic acid, DPPH-2,2-diphenyl-1-picryl-hydrazyl-hydrate, FRAP-ferric reducing/ antioxidant power, $\mathrm{HCl}$-hydrochloric acid, $\mathrm{HgCl}_{2}$. mercuric chloride, HPLC-high performance liquid chromatography, KIN-kinetin, LC-MS/MS-liquid chromatography mass spectrometry, MS-murashige and skoog, NAA-naphthalene acetic acid, NO-nitric oxide, ORAC-oxygen radical absorbance capacity, ROS-reactive oxygen species

\section{ACKNOWLEDGMENT}

The authors thank the Kerala state Council for Science, Environment and Technology, Govt. of Kerala and UGC for providing financial support for the completion of the work.

\section{CONTRIBUTION OF AUTHORS}

Corresponding author (Dr. K. Murugan) has contributed valuable guidance in completing the present work and the first author (Greeshma Murukan) did the whole work in wet lab conditions and is an expert in bio-physical and bio-chmical works.

\section{CONFLICT OF INTERESTS}

Declared none 


\section{REFERENCES}

1. Ann Lila M. Anthocyanins and human health: an in vitro investigative approach. J Biomed Biotechnol 2004;5:306-13.

2. Tsuda T, Horio F, Uchida K, Aoki H, Osawa T. Dietary cyanidin 3$O$-beta-D-glucoside-rich purple corn color prevents obesity and ameliorates hyperglycemia in mice. J Nutr 2003;133:2125-30.

3. Lazze M, Pizzala R, Savio M, Stivala L, Prosperi E, Bianchi L. Anthocyanins protect against DNA damage induced by tertbutyl-hydroperoxide in rat smooth muscle and hepatoma cells. Mutat Res 2003;535:103-15.

4. Lefevre M, Howard L, Most M, Ju Z, Delany J. Microarray analysis of the effects of grape anthocyanins on hepatic gene expression in mice. FASEB J 2004;18:A851.

5. Kong JM, Chia LS, Goh NK, Chia TF, Brouillard R. Analysis and biological activities of anthocyanins. Phytochemicals 2003;64:92333.

6. Rice-Evans C, Packer L, Marcel Dekker NY. editors. Flavonoids in Health and Disease; 1998.

7. Smith M, Marley K, Seigler D, Singletary K, Meline B. Bioactive properties of wild blueberry fruits. J Food Sci 2000;65:352-6.

8. Wang C, Wang J, Lin W, Chu C, Chou F, Tseng T. Protective effect of Hibiscus anthocyanins against tert-butyl hydroperoxide-induced hepatic toxicity in rats. Food Chem Toxicol 2000;38:411-6.

9. Singh J, Bhuyan TC, Ahmed A. Ethnobotanical studies on the mishing tribes of assam with special reference to food and medicinal plant. J Economic Taxonomic Bot 1996;12:350-6.

10. Nayeem N, Karvekar MD. Analgesic and anti-inflammatory activity of the methanolic extract of frontal leaves of Tectona grandis. Int J Pharmacol 2010;8:1531-76.

11. Khera N, Bhargava S. Phytochemical and pharmacological evaluation of Tectona grandis L. Int J Pharm Pharm Sci 2013;5:923-7.

12. Mori T, Sakurai M, Sheigeta J, Youshida K, Kondo T. Formation of anthocyanin from cells cultured from different parts of strawberry plants. J Food Sci 1993;58:788-92.

13. Andersen OM. Semipreparative isolation and structure determination of pelargonidin 3-0- $\alpha$-Lrhamnopyranosyl$(1 \rightarrow 2)-\beta$-D-glucopyranoside and other anthocyanins from the tree Dacrycarpus dacrydioides. Acta Chem Scand Series B: Org Chem Biochem 1988;42:462-8.

14. Blois MS. Antioxidant determinations by the use of a stable free radical. Nature 1958;29:1199-200.

15. Herraiz T, Galisteo J. Endogenous and dietary indoles: a class of antioxidants and radical scavengers in the ABTS assay. Free Radical Res 2004;38:323-31.

16. Ruch RJ, Cheng SJ, Klaunig JE. Prevention of cytotoxicity and inhibition of intracellular communication by antioxidant catechins isolated from Chinese green tea. Carcinogenesis 1989;10:1003-8.

17. Benzie IF, Strain JJ. The ferric reducing ability of plasma as a measure of antioxidant power: The FRAP assay. Ann Biochem 1996;239:70-6.

18. Prior RL, Hoang H, Gu L, Wu X, Bacchiocca M. Assays for hydrophilic and lipophilic antioxidant capacity (oxygen radical absorbance capacity (ORAC) of plasma and other biological and food samples. J Agric Food Chem 2003;51:3273-9.

19. Jakobek L, Seruga M, Kosanovic MM, Novak L. Anthocyanin content and antioxidant activity of various red fruit juices. Deutsche Lebensmitlel-Rundschau 2007;103:58-64.

20. Ramesh $\mathrm{K}$, Kalla Chandra M, Vijaya T. In vitro propagation and ex vitro rooting of Tectona grandis L. f., APNBV-1. Clone J Forest Sci 2009;25:119-26.

21. Narasimhan R, Dhruva B, Paranjpe SV, Kulkarni DD, Mascarenhas AF. Tissue culture of some woody species. Proceedings Indian Acad Sci Section B 1970;71:204-12.

22. Omar MS, Novak FJ. In vitro plant regeneration and ethyl methane sulphonat (EMS) uptake in somatic embryos of date palm (Phonenix dactyliferd). Plant Cell Tiss Org Nutr 1990;20:185-90.

23. Rao R, Vaidyanath K. Callus induction and morphogenesis in sesame (Sesamum indicuni). Adv Plant Sci 1997;10:21-6.
24. Litz RE, Moon PA, Victor MC. Somatic embryogenesis from leaf callus derived from mature trees of cycard Cerato zamiahildae (Gymnospermae). Plant Cell Tis Org Nutr 1995;40:25-31.

25. Saikia M, Shrivastava K, Sureshkumar Singh S. Effect of culture media and growth hormones on callus induction in Aquilaria malaccensis Lam., a medicinally and commercially important tree species of North East India. Asian J Biol Sci 2013;6:96-105.

26. Meyer HJ, Van-Staden J. The in vitro production of anthocyanin from callus cultures of Oxalis linearis. Plant Cell Tiss Org Cult 1994;40:55-8.

27. Taha HS, Abd El-Rahman RA, Fathalla MA, Aly UE. Successful application for enhancement and production of anthocyanin pigment from calli cultures of some ornamental plants. Austr J Basic Appl Sci 2008;2:1148-56.

28. Maharik N, Elgengaihi S, Taha H. Anthocyanin production in callus cultures of Cratae gussinaicaboiss. Int J Acad Res 2009;1:30-4.

29. Aksoy L, Kolay E, Agiionii Y, Aslan Z, Kargioglu M. Free radical scavenging activity, total phenolic content, total antioxidant status, and total oxidant status of endemic Thermopsis turcica. Saudi J Biol Sci 2013;20:235-9.

30. Adedapo, Jimoh F, Afolayan A. Comparison of the nutritive value and biological activities of the acetone, methanol and water extracts of the leaves of Bidens pilosa and Chenopodium album. Acta Poloniae Pharm Drug Res 2011;68:83-92.

31. Tawaha K, Alali FQ, Gharaibeh M, Mohammad M, El-Elimat T. Antioxidant activity and total phenolic content of selected Jordanian plant species. Food Chem 2007;104:1372-8.

32. Thaipong K, Boonprakob U, Crosby K, Cisneros-Zevallos L, Byrne DH. Comparison of ABTS, DPPH, FRAP, and ORAC assays for estimating antioxidant activity from guava fruit extracts. J Food Comp Anal 2006;19:669-75.

33. Wu X, Beecher GR, Holden JM, Haytowitz DB, Gebhardt SE. Lipophilic and hydrophilic antioxidant capacities of common foods in the United States. J Agric Food Chem 2004;52:4026-37.

34. Seeram NP, Henning SM, Zhang Y, Suchard M, Li Z. Pomegranate juice ellagitannin metabolites are present in human plasma and some persist in urine for up to $48 \mathrm{~h}$. J Nutr 2006;136:2481-5.

35. Borges G, Mullen W, Crozier A. Comparison of the polyphenolic composition and antioxidant activity of European commercial fruit juices. Food Funct 2010;1:73-83.

36. Pillai SS, Navarre Du RA, Bamberg J. Analysis of polyphenols, anthocyanins, and carotenoids in tubers from Solanum tuberosum group phureja, stenotomum and andigena. Am J Potato Res 2013;90:440-50.

37. Kalita D, Jayanty SS. Comparison of polyphenol content and antioxidant capacity of colored potato tubers, pomegranate and blueberries. J Food Process Technol 2014;5:1-7.

38. Nile SH, Kim DH, Keum Y. Determination of anthocyanin content and antioxidant capacity of different grape varieties. Cienc Tec Vitivinic 2015;30:60-8.

39. Brewer MS. Natural Antioxidants: sources, compounds, mechanisms of action, and potential applications. Compr Rev Food Sci Food Saf 2011;10:221-47.

40. Pasko P, Barton H, Zagrodzki P, Gorinstein S, Folta M, Zachwieja Z. Anthocyanins, total polyphenols and antioxidant activity in amaranth and quinoa seeds and sprouts during their growth. Food Chem 2009;115:994-8.

41. Dai L, Dong X, Ma H. Antioxidative and chelating properties of anthocyanins in Azolla imbricata induced by cadmium. Pol J Environ Stud 2012;21:837-44.

42. Nikkhah E, Khayami M, Heidari R. In vitro antioxidant activity of berry (Morus alba var. nigra). Int J Plant Prod 2009;3:15-8.

43. Yancheva S, Mavromatis P, Georgieva L. Polyphenol profile and antioxidant activity of extracts from olive leaves. J Central Eur Agric 2016;17:154-63.

44. Figueiredo FJ, Lima VG. Antioxidant activity of anthocyanins from quixabeira (Sideroxylon obtusifolium) fruits. Rev Bras Plantas Med Campinas 2015;17;473-9.

45. Radovanovic AN, Jovancicevic BS, Radovanovic BC, MihajilovKrstev T, Zvezdanovic JB. Antioxidant and antimicrobial potentials of serbian red wines produced from international vitis vinifera grape varieties. J Sci Food Agric 2012;92:2154-61. 
46. Saha S, Verma RJ. Antioxidant activity of polyphenolic extract of Terminalia chebula Retzius fruits. J Taibah University Sci 2016;10:805-12.

47. Ge Q, Ma X. Composition and antioxidant activity of anthocyanins isolated from Yunnan edible rose (An ning). Food Sci Human Wellness 2013;2:68-74.

48. Hemalata B, Sarla S, Kumud U. Preliminary phytochemical, physicochemical, antioxidant and antimicrobial studies of Clematis montana leaves. Int J Curr Pharm Res 2016;8:33-6.

49. Archana D, Dixitha M, Santhy KS. Antioxidant and anti clastogenic potential of Piper longum L. Int J Appl Pharm 2015;7:11-4

50. Rajbir K, Saroj A. Alkaloids-important therapeutic secondary metabolites of plant origin. J Crit Rev 2015;2:1-8.
51. Pavithra S, Manibala J, Ramachandran J. Evaluation of in vitro antioxidant and fibrinolytic activity of flavonoid rich fraction from the whole plant of Wedelia chinensis. Asian J Pharm Clin Res 2016;9:234-9.

52. Packialakshmi B, Sudha G, Charumathy M. Bioactive constituents and antioxidant efficacy of Auricularia polytricha. Asian J Pharm Clin Res 2016;9:125-9.

\section{How to cite this article}

- Greeshma Murukan, Murugan K. Composition of purified anthocyanin isolated from teak and its in vitro antioxidant activity. Int J Pharm Pharm Sci 2017;9(9):258-266. 